\title{
Exploring factors influencing health-seeking decisions and retention in childhood cancer treatment programmes: perspectives of parents in Ghana
}

\author{
Lorna Awo Renner ${ }^{1}$ and Deborah McGill ${ }^{2}$ \\ Ghana Med J 2016; 50(3): 149-156 DOI: http://dx.doi.org/10.4314/gmj.v50i3.6 \\ ${ }^{1}$ University of Ghana School of Medicine and Dentistry, Ghana ${ }^{2}$ University of Liverpool, UK
}

Corresponding author: Professor Lorna A. Renner

E-mail: lornarenner@gmail.com

Conflict of interest: None declared

\section{SUMMARY}

Background: Developing countries such as Ghana have very poor childhood cancer survival rates. There is a need to determine reasons for late presentation and treatment abandonment which are major causes of poor survival. Understanding these issues could inform effective strategies for childhood cancer control in resource-constrained settings.

Aim: To explore factors influencing parental decision-making for children with cancer in Ghana with regard to health seeking and retention in treatment, in order to provide information that will guide Public Health interventions for childhood cancer control.

Method: This exploratory qualitative study was conducted based on an interpretative epistemology using a social constructionist approach. Purposive sampling of parents attending the Paediatric Oncology Unit, Korle Bu Teaching Hospital in Accra, Ghana was undertaken. Twelve semi-structured moderate interviews and two small focus group discussions with a total of seven participants were undertaken. Data analysis was through thematic content analysis.

Results: Five major themes emerged. Knowledge and perceptions revealed a total lack of appropriate knowledge prior to diagnosis. Health-seeking behaviour was determined by interplay of individual and environmental factors. Orthodox medical treatment was largely perceived favourably. The impact of cancer on parents and children included psychological, physical and socioeconomic effects. Financial, spiritual and psychosocial support helped in coping. Parents recommended public education and health financing to address the major barriers.

Conclusion: Broad social determinants and experiences influence parental decision making for children with cancer. This implies Health Promotion strategies with multi-sectorial involvement will be required for effective implementation of the National Strategy for Cancer Control.

Funding: Funded by authors

Keywords: Childhood cancer, parent perspectives, Ghana

\section{INTRODUCTION}

Globally, the annual incidence of childhood cancer is about 140 per one million children under the age of 15 years with175,000 new cases and 96,000 deaths annually. ${ }^{1}$ Ninety percent of these deaths occur in developing countries. $^{2}$ From the early 1960 s with five year survival rates less than $30 \%$, long term survival is now over $75 \%$ in highly developed countries. ${ }^{3}$

Survival for childhood cancers in developing countries is low. ${ }^{4}$ There are several factors for this, but delayed reporting to treatment facilities and abandonment of treatment, are of major concern. ${ }^{4}$ The World Health Organisation (WHO) Global Action Plan seeks to achieve a $25 \%$ reduction in mortality from non- communicable diseases including cancer between 2013 and $2020 .^{5}$ As deaths from preventable infections in childhood are being controlled, deaths from cancer are set to increasingly form a significant percentage of deaths in developing countries. ${ }^{6}$

Health-seeking behaviour is a process of interaction with the health system and is affected by social, environmental and health system factors. ${ }^{7}$ Treatment abandonment is defined as a failure to start or there being a hiatus, not medically indicated, of at least four consecutive weeks during planned treatment. ${ }^{4}$ 
A systematic meta-analysis of studies from LMICs generated abandonment rates of up to $74.5 \%{ }^{8}$ Socioeconomic ${ }^{9,10,11}$ and health system factors such as access to treatment are known causes. ${ }^{12,13}$ In a stuy in Kenya, delays to treatment were mainly due to guardian factors compared to health system factors, being nine and two weeks respectively. ${ }^{14}$ Some studies have reported comparatively longer health system delays. ${ }^{15,16}$ Lack of information, family pressures, financial and hospital detention practices have been noted to affect treatment decisions. ${ }^{17}$ Parents' quest for less traumatic therapy and the attitude of healthcare professionals do influence abandonment. ${ }^{18}$ There is a paucity of studies on parental perceptions and health seeking from Africa. Most studies have focused mainly on abandonment. Early detection improves outcomes and so this study is important as it explores reasons for delayed presentation. With regards to abandonment, how parents cope so as to be able to stay in the treatment programme is critical and is studied here. There is a gap in this area in the few published African studies. The aim of this study was to explore factors influencing parental health-seeking decision making for children with cancer in Ghana in order to generate information that would guide Public Health interventions for childhood cancer control.

\section{METHODS}

Ethical approval was obtained from University of Liverpool and local ethical approval from the University of Ghana School of Medicine and Dentistry Ethical and Protocol Review Committee prior to study commencement.

\section{Study design}

An exploratory qualitative study design utilizing semistructured interviews and focus group discussions (FGD) was employed. Setting: The study was conducted in the Department of Child Health, Paediatric Oncology Unit (POU) at the Korle Bu Teaching Hospital (KBTH) in Accra, Ghana, West Africa. This POU, the larger of only two in Ghana where children with cancer are treated, receives referrals from all regions of the country. About 140 cases are admitted to the unit annually. ${ }^{19}$ The interviews were undertaken in a separate quiet room in the POU Day Care Unit, ensuring confidentiality.

\section{Sampling/study population}

Purposive sampling of parents of children with cancer attending the POU was utilized to recruit 12 participants for one-to-one, semi-structured interviews and 7 participants for 2 FGDs. The parents, who voluntarily agreed to participate, had children diagnosed with cancer between four weeks to six months prior to the interview and were on treatment with a curative intent.
Participants had to be able to speak either English or Akan, languages the researcher was fluent in and spoken by the majority of people in Ghana. ${ }^{20}$ Written informed consent was obtained prior to commencement of interviews. Unique study numbers for participants ensured confidentiality and anonymity.

\section{Sample recruitment}

Participant recruitment was undertaken from January to March 2015. Participant information sheets in English or Akan were distributed to all eligible parents at the clinic by the senior nurse-in-charge and read to illiterate parents by her. Those who agreed to participate were contacted by the researcher.

\section{Data collection}

Based on a social constructionist approach, a semistructured interview guide with open-ended questions was utilized. Pilot testing of the interview guide with two parents and one focus group was undertaken in January 2015 . No changes to the data collection instrument were made except to shift the sensitive question about their child being cured almost to the end of the interview. Data from the pilots, being information rich, were included in the study. The use of FGDs was intended to encourage conversation, as well as to minimize potential power imbalance effects of the researcher over participants so they could be more expressive of negative views. ${ }^{21}$ This, being considered a form of triangulation also helped validate the interviews. ${ }^{22}$

Key topics included were: Understanding of cancer; Decisions taken and reasons; Experiences of parent and child; Recommendations to promote appropriate health seeking and retention. The conversations were digitally recorded with permission, notes taken and recordings transcribed. Duration of interviews lasted 30 to 59 minutes and FGDs 63 and 84 minutes each. All the transcriptions and translations were done by the same researcher so as to ensure accuracy and to aid familiarity with the data. ${ }^{23}$

\section{Analytical approach}

After transcription the data was analysed using thematic content analysis (TCA). Based on the empirical data, inductive coding was performed. Codes were then grouped under subthemes by comparing participant accounts by means of a rigorous iterative method. Using the process of induction, common subthemes were recognised leading to the emergence and identification of principal themes. The study objectives also informed the deduction of themes which were thereby derived both a priori and by induction. 


\section{RESULTS}

The participant demographic details are shown in Table 1. Themes and subthemes are shown in Table 2. Direct quotes are presented here to support themes. R represents individual interviews and $\mathrm{G}$ focus group participants.

Table 1 Demographic details of Participants

\begin{tabular}{|c|c|}
\hline Characteristic & Participants' Demographic Details \\
\hline Gender & $\begin{array}{l}\text { Females }-13 \\
\text { males }-6\end{array}$ \\
\hline Age & $\begin{array}{l}\text { Mean age }-36 y r s \\
\text { (range: } 25-49 y r s)\end{array}$ \\
\hline Nationality & All Ghanaian \\
\hline Ethnic group & $\begin{array}{l}\text { Akan }-9, \\
\text { Ewe }-3 \\
\text { Ga }-2 \\
\text { Nzema - } 2 \\
\text { Northern - } 3\end{array}$ \\
\hline Language & $\begin{array}{l}\text { English }-7 \\
\text { Akan - } 12\end{array}$ \\
\hline Education & $\begin{array}{l}\text { Tertiary }-4 \\
\text { Secondary }-7 \\
\text { Primary }-5 \\
\text { None }-3\end{array}$ \\
\hline Occupation & $\begin{array}{l}\text { Professional - } 5 \\
\text { Non-professional - } 12 \text { (eg, farmers, trad- } \\
\text { ers) } \\
\text { Unemployed - } 2\end{array}$ \\
\hline Religion & $\begin{array}{l}\text { Christian - } 15 \\
\text { Moslem - } 4\end{array}$ \\
\hline
\end{tabular}

Table 2 Themes and Subthemes

\begin{tabular}{|c|c|}
\hline Theme: & Subtheme: \\
\hline \multirow{3}{*}{$\begin{array}{l}\text { 1. Knowledge and Percep- } \\
\text { tions about Cancer }\end{array}$} & 1.1 Knowledge of cancer \\
\hline & 1.2 Education source for cancer \\
\hline & 1.3 Perceived Causes of cancer \\
\hline \multirow{5}{*}{$\begin{array}{l}\text { 2. Health-seeking Behaviour } \\
\text { and its Determinants }\end{array}$} & 2.1 Delays to treatment \\
\hline & 2.2 Decision makers \\
\hline & $\begin{array}{l}\text { 2.3 Determinants influencing paren- } \\
\text { tal treatment decisions }\end{array}$ \\
\hline & 2.4 Actions taken by Parents \\
\hline & $\begin{array}{l}2.5 \text { Complementary and Alternative } \\
\text { medicine use and perspectives }\end{array}$ \\
\hline \multirow{4}{*}{$\begin{array}{l}\text { 3. Perspectives about Or- } \\
\text { thodox Medical Treatment } \\
\text { Received }\end{array}$} & $\begin{array}{l}\text { 3.1 Communication and counselling } \\
\text { on disease }\end{array}$ \\
\hline & $\begin{array}{l}3.2 \text { Health worker interactions with } \\
\text { parents and children }\end{array}$ \\
\hline & 3.3 Physical effects of treatment \\
\hline & $\begin{array}{l}3.4 \text { Perspective of parents about } \\
\text { treatment }\end{array}$ \\
\hline \multirow[t]{5}{*}{$\begin{array}{l}\text { 4. Impact of Cancer on } \\
\text { Parents and Children }\end{array}$} & $\begin{array}{l}\text { 4.1 Psychological effects throughout } \\
\text { disease course }\end{array}$ \\
\hline & $\begin{array}{l}\text { 4.2 Perceived stigma and discrimi- } \\
\text { nation against parents and children }\end{array}$ \\
\hline & $\begin{array}{l}4.3 \text { Relationships with family, } \\
\text { friends }\end{array}$ \\
\hline & 4.4 Effects on normal life \\
\hline & 4.5 Resources for coping \\
\hline \multirow{2}{*}{$\begin{array}{l}\text { 5. Recommendations to } \\
\text { Enable Early Presentation } \\
\text { and Retention in Medical } \\
\text { Treatment Programme }\end{array}$} & 5.1 Public awareness creation \\
\hline & 5.2 Access to treatment \\
\hline
\end{tabular}

\section{Knowledge and Perceptions about Cancer}

All parents, except one, heard about childhood cancer for the first time when their child was admitted to KBTH POU. They associated cancer with death, based on adult experiences and this provoked anxiety.

R7 "Sometimes, it is difficult ....you are told the child has cancer, ah, this little child can get cancer, ah, it is frightening."

The media (television, radio) was a source of adult cancer information for several parents. Only one had prior knowledge of childhood cancer through media. All had been informed about childhood cancer by health professionals at the tertiary facility with only three at the referring hospital. Other information sources were friends, relatives, pastors, herbalists. Parents also educated each other based on their experiences.

R2 “...they [parents] use theirs [experience] as an example. That 'you see, this is how your child, this nice boy, this is how he will turn [become]'. So they put fear [frightened me]."

A few parents knew causes of adult cancers including lifestyle habits and aging. This contrasted with a high level of wrong perceptions such as money in close contact with skin as a cause, trauma being causative, cancer being infectious and spiritual causation.

R11 "if the person ....is not into smoking, drinking and he happens to get some [cancer], what comes to our mind, maybe it's a spiritual attack...."

\section{Health-Seeking Behaviour and its Determinants}

The delay from the time it was first noticed by the family to presentation varied from two weeks to over a year. Delays due to service factors included rescheduled appointments because of the unavailability of physicians, various treatments being given at health facilities or drug stores and long waits for results of investigations

R1 "On the date when we went they said it was a holiday. We were given several other appointments aaaah and finally when he saw us he also said that the child's eyeball was dead..."

Parental factors included lack of knowledge, financial difficulties, fears about treatment and a few using alternative therapies such as herbal treatments, faith healing and self-medication. Most respondents said decisions followed combined parental discussions but one woman stated she had to wait for her husband's directives. 
G2 “As for me, ((sigh, sucks teeth)), it's true, if the child is not well, I cannot take the child to hospital quickly. It takes some time.... The father, the father says we should go to hospital."

For initially accessing care, although parental perceptions and financial issues were major factors, the influence of relatives and friends was important. Once the diagnosis was made, additional factors that affected decision making were; information given by health workers, treatment fears, influence of other parents and experiences in hospital.

R4 "...they would do her surgery, firstly, and the hair would go off [bald]. That is when I said that mmm, then I would not allow the doctors to attend to my daughter.... But after that, my husband talked to me and he said '(R4) look, our daughter is important, let's agree'. Because they said ...plenty money is involved... That is why I said no."

Once contact was made with a health facility all except four complied with medical advice. Three feared effects of their child losing a body part through surgery and so defaulted.

$\mathrm{R} 7$ "That is what is worrying us. If they remove a kidney that means it's only one that will be working. You see. And in the future something might happen and the other one may ( ) and if it has to be removed that will mean death."

Combining orthodox medicine with prayers, believing God would ultimately heal their child, was universally expressed. Combining native (herbal) with orthodox medicine was deemed inadvisable. Few parents tried native medicine, not knowing whether it was effective and the few who did concluded it was not useful.

R6 "Her grandma said she wouldn't allow us to bring her [child] but there is native medicine that would work. So that day, she took us ... and she was given, given medicine. ...I told her father that I am worried about the child's condition. I also don't understand the [native] medicine... So when grandma left, that night, we took public transport and came here."

\section{Perspectives about Orthodox Medical Treatment Received}

All the parents mentioned information given them about the diagnosis and treatment, demonstrating that for the most part they were well informed.

R2 "I think doctors are very good here because everybody was trying to talk to you very calm, they tell you what will happen... they educate you about the whole thing."

But the approach sometimes affected parents.

R3 “...you see, they [doctors] went straight forward. You see in matters of err, medicals...get the clinical psychologist to prepare your [parent's] mind that this is what we are going to tell you..."

Of concern was the expressed difficulty of parents asking doctors questions, despite doctors being described as being 'pleasant'.

R3 "You might not have the courage to ask them [doctors] questions. ...the stress you go through will not help you think through that oh, these are some of the questions when I see the doctor I will ask."

Most parents were pleased with the interactions, stating that health professionals were friendly, empathetic, but a few health workers displayed negative attitudes leading to perceptions of them looking down on parents.

Distressing side effects were due mainly to the vomiting which some parents however accepted as evidence that the treatment was working.

G2 "We pray that the child should vomit so that the disease will be cured."

Parents appeared to cope as they had been informed about side effects prior to starting treatment.

R2 "They prepare your mind concerning the ... treatment you are going to go through. So even if you are going through you know they've already tell [told] you this is what will happen."

Uppermost on all minds was the cost involved, including wasted resources in the event of death. Notwithstanding, they were pleased with the treatment as it was perceived from their observations to be effective.

\section{Impact of Cancer on Parents and Children}

The diagnosis evoked a wide range of emotions from initial anxiety and sadness to happiness once the children were perceived to be responding to treatment. Feelings of guilt were expressed by a parent:

G5 "The first day I heard of this, I was baffled ... where is this one [cancer] from or is it due to my misdeeds...?" 
All parents except one expressed unwillingness to disclose the diagnosis to others. Stigma, enacted and felt, associated with this disease was the reason for this.

G6 "...if the child goes anywhere, if he goes to his friend ....... they will say the child has a disease, they will not allow you [friend] to eat with him [child]. You see, the children will be scared of him. ......... his friend will trouble him so much that the child will stop school."

The disease and treatment had profound effects on their lives. Work was affected. All the children, even some siblings, had experienced interruptions to schooling.

All parents relied heavily on their personal faith and spiritual support to cope. Funds from relatives, friends, the church or provision of drugs was crucial. Adequate information and staff attitude helped all parents accept and continue treatment. Seeing their child and others improve was also encouraging.

\section{Recommendations to Enable Early Presentation and Retention in Orthodox Medical Treatment Pro- gramme}

All the parents were of the view that being unaware that their child could possibly be suffering from cancer contributed to delays. Public education activities in schools and the community using media to raise awareness including educating health workers were deemed very important. Information provided consistently for parents was stated as encouraging retention.

R4 "...you have to encourage them with words every day. That is what is good because that is what helped me to stay, to agree."

Financial support and treatment being made available under the NHIS was expressed as a necessity. Health workers being more approachable would encourage parents to seek appropriate health care and having a more efficient patient review system at lower level facilities would encourage attendance.

\section{DISCUSSION}

This study provides important insights as to factors, ranging from the individual level through to national policy levels, that influence decisions on uptake of and persistence or otherwise on treatment for childhood cancer in a Low Middle Income Country.

The almost universal lack of knowledge about childhood cancer prior to their child's diagnosis indicates this would be a major factor in determining perceptions about illness severity and subsequent health-seeking decisions. Parents equating cancer with death implies potential adverse decisions, if they are not wellinformed about good treatment outcomes. ${ }^{17,24}$ The media being main sources of community information means use of this by health promoters could be an effective method for public health education. The knowledge exhibited by all parents in this study suggests that relevant information, if given consistently by health professionals is understood. 25

The unknown causation of most childhood cancers could re-inforce perceived supernatural causation and lead to the quest for alternative therapies. ${ }^{26}$ All parents combined faith with orthodox medicine, a very common practice found amongst adult patients in this setting. ${ }^{27}$

Parents seeking orthodox treatment suggest confidence, initially, in the biomedical health system. The diagnostic delays demonstrate the necessity for efficiency in the health system. Treatment fears, due to concerns about its effects, leading to treatment refusal or abandonment, reinforce the need for provision of adequate information and counselling. ${ }^{28}$ The importance of parents being well-informed and understanding the treatment trajectory is evident. Parents being unable to ask questions, ${ }^{9}$ is of concern since cooperation with treatment improves when clients feel empowered enough to make input into treatment decisions. ${ }^{29}$

The significance of health professional attitudes in shaping parental perspectives is evident. Negative attitudes of health workers may lead to feelings of loss of selfesteem as articulated by some parents. This could further exacerbate psychological effects of their child's disease on parental self-worth. The significance of pleasant and encouraging attitudes exhibited by health professionals in shaping positive parental perspectives is evident in this setting. A holistic approach by service providers is very important as health care providers focussing only on the physical disease could lead to parents seeking alternative therapies from more empathetic practitioners. ${ }^{18}$

Psychological effects can be quite traumatic ${ }^{30,31}$, making the involvement of a clinical psychologist in multidisciplinary teams important. The perception of societal stigma, with its attendant stresses ${ }^{32}$ denotes a lack of knowledge and understanding about cancer in the community. This calls for public education.

Considering resources that help parents cope and be resilient, this study confirms financial support and ease of access to drugs are crucial. The need for spiritual support and relying on personal faith ${ }^{33,34}$ being key coping tools, signify religious representation in multidisciplinary teams would be beneficial. 
Acceptance of side effects by parents, who have been given prior knowledge of such, continues to buttress good communication between health workers and parents as important.

The benefit of public education has been demonstrated by others ${ }^{35}$ and so educational campaigns to create and maintain awareness are required. The importance of community involvement in educational programmes is supported by the fact that some parents seek treatment from community pharmacies, herbalists and churches, as also reported in Nigeria. ${ }^{15}$ The ability to impart the requisite information to parents at all levels of the health system is important, potentially reducing parental delays and abandonment.Good communication skills a necessity.

Financial implications play a prominent role in determining decisions. ${ }^{9,11}$ This is a huge barrier for uptake and continued use regardless of health service quality. Health financing for childhood cancer with National Health Insurance coverage is strongly recommended. Fair financing, health provision and responsiveness should be intrinsic goals of health systems. ${ }^{36}$

\section{Limitations}

The population was restricted to those who had sought orthodox treatment so some responses, for example about complementary and alternative medicine, would not be representative of the general population. Language restrictions meant parents unable to speak English or Akan, were excluded with possible limitation of a broader understanding of sociocultural factors. Further research exploring psychosocial issues affecting children with cancer in Low and Middle Income Countries (LMICs) so as to improve their quality of life is required.

\section{CONCLUSIONS}

Parents' perceptions of the health system, including delays in appointments and negative attitudes of some providers, should help inform policymakers for capacity building, design and implementation of service delivery, placing emphasis on responsiveness. Health-seeking behaviour of parents with children affected by cancer and their retention in treatment is determined, from an ecological perspective, by wide-ranging interlinked social determinants from the individual through to national policy levels.

These findings should help direct health promotion strategies $^{37}$ as behaviour change and choices require an enabling environment. Implementation of country National Cancer Control plans which would include capacity building is of paramount importance if outcomes for childhood cancer are to be improved. There is the need to strengthen the health system by a multi-sectorial approach, improving access, quality of care and health financing so as to enhance equity and health equality for children with cancer in Ghana and similar LMICs.

\section{ACKNOWLEDGEMENT}

Our appreciation goes to all the parents of children with cancer at the Paediatric Oncology Unit, Korle Bu Hospital who shared their experiences. Mrs Rebecca Armah for the role she played in recruitment. We also acknowledge the dedicated nursing and medical team who care for affected children.

\section{REFERENCES}

1. American Childhood Cancer Organisation (2014) Childhood Cancer Statistics, [Online]. Available at: http://www.acco.org/information/aboutchildhoodca ncer/childhoodcancerstatistics.aspx (Accessed: 9 July 2014)

2. Rodriguez-Galindo, C., Friedrich, P., Morrissey, L. \& Frazier, L. Global Challenges in Pediatric Oncology, Curr Opin in Pediatr 2013:25: 3-15

3. Stiller, C.A., Kroll, M.E. \& Pritchard-Jones, K. Population Survival from Childhood Cancer in Britain during 1978-2005 by Eras of Entry to Clinical Trials, Ann Oncol 2012:23:2464-2469

4. Mostert, S., Arora, R.S., Arreola, M. Bagai, P., Friedrich, P., Gupta, S., Kaur, G., Koodiyedath, B. \& Kulkarni, K. Abandonment of Treatment for Childhood Cancer: Position Statement of A SIOP PODC Working Group, Lancet Oncol 2011:12:719-720

5. World Health Organisation (2015) Global Action Plan 2013 - 2020. [Online] Available at: http://apps.who.int/iris/bitstream/10665/94384/1/97 89241506236_eng.pdf (Accessed: 15 March 2015)

6. Ribeiro, R.C., Pui, C.H. Improving Childhood Cancer Treatment in Developing Countries, New Engl J Med 2005:352:2158-2160,

7. Mackian S. A Review of Health Seeking Behaviour: Problems and Prospects. Internal Concept Paper. Health Systems Development Programme, London School of Hygiene and Tropical Medicine, London, 2001.

8. Gupta, S., Yeh, S., Martiniuk, A., Lam, C.G., Chen, H-Y., Liu, Y-L., Tsimicalis, A., Arora, R.S. \& Ribeiro, R.C. The Magnitude and Predictors of Abandonment of Therapy in Paediatric Acute Leukaemia in Middle-Income Countries: A Systematic Review and Meta-Analysis, Eur J Cancer, 2013:49:25552564

9. Israels T., Chirambo C., Caron H., de Kraker, J., Molyneux, E. \& Reis, R. The Guardians' Perspective on Paediatric Cancer Treatment in Malawi and 
Factors Affecting Adherence, Pediatr Blood Cancer 2008:51:639-642

10. Bonilla, M., Rossell, N., Salaverria, C., Gupta, S., Barr, R., Sala, A., Metzger, M.L. \& Sung, L. Prevalence and Predictors of Abandonment of Therapy among Children with Cancer in El Salvador. Int. J Cancer 2009:125:2144-2146

11. Njuguna, F., Mostert, S., Slot, A., Langat, S., Skiles, J., Sitaresmi, M.N., van de Ven, P.M., Musimbi, J., Muliro, H., Vreeman, R.C. \& Kaspers, G.J.L. Abandonment Of Childhood Cancer Treatment In Western Kenya, Arch Dis Child 2014:99:609-614

12. Arora, R.S., Eden, T. \& Pizer, B. The Problem of Treatment Abandonment in Children from Developing Countries with Cancer, Pediatr Blood Cancer 2007:49:941-946

13. Sitaresmi, M.N., Mostert, S., Schook, R.M., Sutaryo \& Veerman, A.J.P. Treatment Refusal and Abandonment in Childhood Acute Lymphoblastic Leukemia in Indonesia: An Analysis of Causes and Consequences, Psycho Oncology 2010:19:361-367

14. Buckle, G.C. Collins, Sumba, P.O., Nakalema, B., Omenah, D., Stiffler, K., Casper, C., Otieno, J.A., Orem, J. \& Moormann, A.M. Factors Influencing Time To Diagnosis And Initiation Of Treatment Of Endemic Burkitt Lymphoma Among Children In Uganda And Western Kenya: A Cross-Sectional Survey, Infect Agents Cancer 2013:8:36 [Online]. Available at: doi:10.1186/1750-9378-8-36

15. James, B.O, Aayi, S.O, Ogun, O.A. \& Oladokun, R.E. Factors Influencing Time to Diagnosis of Childhood Cancer in Ibadan, Nigeria, Afr Health Sci 2009:9:247-253

16. Stefan, C. and Siemonsma, F. Delay and Causes of Delay in the Diagnosis of Childhood Cancer in Africa, Pediatr Blood Cancer 2011:56:80-85

17. Mostert, S., Njuguna, F., Langat, S.C., Slot, A.J.M., Skiles, J., Sitaresmi, M.N., van de Ven, P.M., Musimbi, J., Vreeman, R.C. \& Kaspers, G.J.L. Two Overlooked Contributors to Abandonment of Childhood Cancer Treatment in Kenya: Parents' Social Network and Experiences with Hospital Retention Policies, Psycho-Oncology 2014:23:700707

18. Yeh, C.H., Lin, C.F., Tsai, J.L. et al. Determinants of Parental Decisions on 'Drop Out' from Cancer Treatment for Childhood Cancer Patients. J Adv Nurs, 1999:30:193-199

19. Segbefia, C., Renner, L.A., Dei-Adomakoh, Y.A., Baeta, N., Ekem, I. Changing Pattern of Childhood Cancers at Korle $\mathrm{Bu}$ Teaching Hospital, Accra, Ghana, Postgrad Med J Gh 2013:2:65-67

20. Rutgers (2014) Akan (Twi) at Rutgers [Online]. Available at: http://www.amesall.rutgers.edu/languages/128-akan-twi

21. Schneider, H. and Palmer, N. Getting to the Truth? Researching User Views of Primary Health Care Health Policy Plan 2002;17(1):32-41

22. Lambert, S.D. and Loiselle, C.G. Combining Individual Interviews and Focus Groups to Enhance Data Richness, J Adv Nurs 2008;62:228-237

23. Draper, A. \& Swift, J.A. Qualitative Research in Nutrition and Dietetics: Data Collection Issues, $J$ Hum Nut Diet 2010;24:3-12

24. Spinetta, J., Masera, G., Eden, T., Oppenheim, D., Martins, A.G., van Dongen-Melman, J., Siegler, M., Eiser, C., Arush, M.W.B., Kosmidis, H.V. \& Jankovic, M. Refusal, Non-Compliance and Abandonment of Treatment in Children and Adolescents with Cancer: A Report of the SIOP Working Committee on Psychosocial Issues in Paediatric Oncology. Med Pediatr Oncol 2002;38:114-117

25. Mostert, S., Sitaresmi, M.M., Gundy, C.M., Janes, V., Sutaryo \& Veerman, A.J.P. Comparing childhood leukaemia treatment before and after the introduction of a parental education programme in Indonesia. Arch Dis Child 2010;95:20-25

26. Abubakar, A., Van Baar, A., Fischer, R., Bomu, G., Gona, J.K. \& Newton, C.R. Socio-Cultural Determinants of Health-Seeking Behaviour on The Kenyan Coast: A Qualitative Study, Plos One 2013; 8(11) [Online]. Available at: E71998. doi:10.1371/journal.pone.0071998 (Accessed: 5 December 2014)

27. Yarney, J., Donkor, A., Opoku, S.Y., Yarney, L., Agyeman-Duah, I., Abakah, A.C. \& Asampong, E. Characteristics of Users and Implications for the Use of Complementary and Alternative Medicine in Ghanaian Cancer Patients Undergoing Radiotherapy and Chemotherapy: A Cross- Sectional Study, BMC Complement Altern Med 2013;13:16, [Online]. Available At: www.biomedcentral.com/1472-6882/13/16 (Accessed: 19 September 2014)

28. Wang, Y., Jin, R., Xu, J. \& Zhang, Z. A Report about Treatment Refusal and Abandonment in Children with Acute Lymphoblastic Leukemia in China, 1997-2007. Leuk Res 2011;35:1628-1631,

29. Pyke-Grimm, K., Stewart, J., Kelly, K., \& Degner, L. Parents of Children with Cancer: Factors Influencing their Treatment Decision Making Roles, $J$ Pediatr Nurs 2006;21:350-361

30. Hocking, M.C., Kazak, A.A., Schneider, S., Barkman, D., Barakat, L.P. \& Deatrick, J.A. Parent Perspectives on Family-Based Psychosocial Interventions in Pediatric Cancer: A Mixed-Methods Approach, Support Care Cancer 2014;22:1287-1294

31. Papaikonomou, M \& Nieuwoudt, J. Exploring Parents' Stories of Coping with Their Child's Cancer: 
A Qualitative Study, $S$ Afr $J$ Psychology 2004;34:283-300

32. Link, B.G. and Phelan, J.C. Stigma and its Public Health Implications, Lancet 2006;367:528-529

33. Brody, A. C. \& Simmons, L.A. Family Resiliency during Childhood Cancer, The Father's Perspective, J Pediatr Oncol Nurs 2007;24:152-165

34. Fletcher, P.C., Schneider, M.A. \& Harry, R J. How Do I Cope? Factors Affecting Mothers' Abilities to Cope with Pediatric Cancer, J Pediatr Oncol Nurs 2013;27(5), pp. 285-298

35. Leander, C., Fu, L.C., Pena, A., Howard, S.C., Rodriguez-Galindo, C., Wilimas, J.A., Ribeiro, R.C. \& Haik, B. Impact of an Education Program on Late Diagnosis of Retinoblastoma in Honduras, Pediatr Blood Cancer 2007;49:817-819
36. World Health Organisation, Darby C, Valentine N, Murray Cl, De Silva A. World Health Organization: Strategy On Measuring Responsiveness. In GPE Discussion Paper Series, 23. WHO, 2000 [Online]. Available at: http://www.who.int/healthinfo/paper23.pdf (Accessed: 21 October 2013)

37. World Health Organization Annex A: List of All Recommendations. In: Closing the Gap in a Generation: Health Equity through Action on the Social Determinants of Health. Geneva: World Health Organization 2008 [Online]. Available at:

http://whqlibdoc.who.int/publications/2008/9789241563

703_eng_annex.pdf $\boldsymbol{\bullet}$ 